\title{
Chemotherapy versus supportive care alone in pediatric palliative care for cancer: comparing the preferences of parents and health care professionals
}

\author{
Deborah Tomlinson MN RN, Ute Bartels MD, Janet Gammon RN, Pamela S. Hinds PhD RN, \\ Jocelyne Volpe MN RN, Eric Bouffet MD, Dean A. Regier PhD, Sylvain Baruchel MD, Mark Greenberg MD, \\ Maru Barrera PhD, Hilary Llewellyn-Thomas PhD, Lillian Sung PhD MD
}

See related commentary by Knapp and Komatz at www.cmaj.ca/lookup/doi/10.1503/cmaj.111557

Competing interests: None declared.

This article has been peer reviewed.

Correspondence to:

Dr. Lillian Sung,

lillian.sung@sickkids.ca

CMAJ 2011. DOI:10.1503

/cmaj.110392

\section{ABSTRACT}

Background: The choice between palliative chemotherapy (defined as the use of cytotoxic medications delivered intravenously for the purpose of our study) and supportive care alone is one of the most difficult decisions in pediatric oncology, yet little is known about the preferences of parents and health care professionals. We compared the strength of these preferences by considering children's quality of life and survival time as key attributes. In addition, we identified factors associated with the reported preferences.

Methods: We included parents of children whose cancer had no reasonable chance of being cured and health care professionals in pediatric oncology as participants in our study. We administered separate interviews to parents and to health care professionals. Visual analogue scales were shown to respondents to illustrate the anticipated level of the child's quality of life, the expected duration of survival and the probability of cure (shown only to health care professionals). Respondents were then asked which treatment option they would favour given these baseline attributes. In addition, respondents reported what factors might affect such a decision and ranked all factors identified in order of importance. The primary measure was the desirability score for supportive care alone relative to palliative chemotherapy, as obtained using the threshold technique.

Results: A total of 77 parents and 128 health care professionals participated in our study. Important factors influencing the decision between therapeutic options were child quality-of-life and survival time among both parents and health care professionals. Hope was particularly important to parents. Parents significantly favoured chemotherapy (42/77, $54.5 \%$ ) compared with health care professionals $(20 / 128,15.6 \% ; p<0.0001)$. The opinions of the physician and child significantly influenced the parents' desire for supportive care; for health care professionals, the opinions of parents and children were significant factors influencing this decision.

Interpretation: Compared with health care professionals, parents more strongly favour aggressive treatment in the palliative phase and rank hope as a more important factor for making decisions about treatment. Understanding the differences between parents and health care professionals in the relative desirability of supportive care alone may aid in communication and improve end-of-life care for children with cancer.
$\mathrm{D}$ espite the substantial improvements in rates of cure among children with cancer, some children will have progressive or recurrent disease and will die. ${ }^{1}$ Cancer remains the second most common cause of death for North American children between 5 and 14 years of age..$^{2-4}$ When cure becomes unlikely, parents and health care professionals are often faced with the decision to continue further aggressive treatments or to provide relief from symptoms alone. ${ }^{1}$
The choice between palliative chemotherapy and supportive care alone is one of the most important and difficult decisions for parents of children whose disease cannot be cured. ${ }^{5}$ At this point, the goals of therapy are usually to maximize the child's quality and length of life and to ensure respect for the family's and child's preferences. ${ }^{6}$

Given the difficult nature of this decision, it is worthwhile to compare and contrast the perspectives of parents and health care professionals. 
Discordance in these perspectives could heighten the anxiety felt by patients and parents and might lead to their dissatisfaction with the care received. One qualitative study that interviewed parents of children with recurrent cancer found that "fearing disagreement with staff" was an important negative factor in decision-making.? However, little is known as to whether the attitudes of parents and health care professionals toward therapeutic options are congruent.

The goal of this study was to compare the strength of preference between parents and health care professionals for supportive care alone versus palliative chemotherapy for children whose cancer has no reasonable chance of being cured, and to determine how specific factors affect these preferences.

\section{Methods}

\section{Focus group prephase}

Before the study began, we held a focus group with 12 parents whose children had died of cancer. ${ }^{8}$ Together with the participants, we identified the range of factors that parents consider important in choosing between supportive care and palliative chemotherapy. Given the sensitive nature of our study, we also asked the focus group to test our visual aids and interview script to ensure that we minimized the potential for causing additional distress to our participants.

\section{Participants}

Parents of children under 18 years of age with cancer that was considered to have no reasonable chance of cure $(<5 \%$ chance of long-term survival according to their attending physician), and who were not at the point of actual decisionmaking, were evaluated for eligibility in our study. Inclusion criteria were the ability to speak and read English and provide informed consent. Responses from only one parent per child were included.

For health care professionals, we sampled staff physicians practising pediatric oncology, senior fellows in training with at least one year of dedicated training in pediatric oncology and nurses and social workers who worked exclusively with children with cancer.

\section{Study design}

The Research Ethics Board at The Hospital for Sick Children approved this study, and written informed consent was obtained from all participants. A single research nurse (Deborah Tomlinson) conducted all interviews using kits with prepared scripts and visual aids that had been pilot-tested with the focus group. Parents were interviewed in inpatient or outpatient settings, or in their homes, according to their wishes.

There were slight differences between the interview kits used for parents and those used for the health care professionals. Parents and health care professionals were both asked to consider a hypothetical scenario in which the child's treatment was no longer working and no further treatments were available to cure the child's illness. Both kits used threshold tasks ${ }^{9,10}$ (Appendix 1, available at www.cmaj.ca/lookup/suppl/doi:10 .1503/cmaj.110392/-/DC1) for assessing desirability. The kit used for health care professionals involved threshold tasks working with three therapeutic attributes: child's anticipated quality of life, expected survival time and probability of cure. Parents in the focus group had strongly recommended that the probability of cure not be used in the interview kit for parents. The focus group felt that because the scenario specified that curative treatments were no longer available, it would appear contradictory, and likely cause emotional distress, if the interviewer then subsequently used probability of cure in a threshold task. As such, the parents' set worked with just the first two therapeutic attributes. Appendix 1 details the structure of the interview and the steps taken to obtain desirability scores for supportive care versus aggressive chemotherapy from parents and health care professionals.

Participants were also provided with a list of factors (identified by the focus group) that could potentially affect their responses to the threshold tasks and asked to rank them in order of personal importance. In addition, parents were given the opportunity to include any further factors that they considered important (Appendix 1).

\section{Assessing potential predictors}

We assessed the impact of reporting others' opinions on the indirectly derived desirability scores for supportive care relative to chemotherapy. For parents, the interviewer repeated the two threshold tasks four times in random order, after stating that the physician strongly prefers chemotherapy, that the physician strongly prefers supportive care, that the child strongly prefers chemotherapy, and that the child strongly prefers supportive care. For health care professionals, the three threshold tasks were repeated four times with similar statements about the preferences of the parents and the child.

In addition, parents were asked to estimate their own and their child's current overall quality of life during the previous week using a horizontal $10-\mathrm{cm}$ visual analogue scale anchored at 0 (worst possible quality of life) and 10 (best possible quality of life). 


\section{Statistical analysis}

Our sample size estimations suggested that 75 participants in the parent group and 75 in the health care professional group would provide at least $80 \%$ power to detect a $20 \%$ across-group difference in desirability scores. However, we increased the size of the sample of health care professionals to allow us to explore potential relations between their characteristics and the desirability scores they gave to supportive care.

The primary measure was the desirability of supportive care alone versus palliative chemotherapy. Desirability scores were indirectly identified in each threshold task by the point at which respondents switched to their initially rejected option (Appendices 3-5, available at www.cmaj.ca /lookup/suppl/doi:10.1503/cmaj.110392/-/DC1). Higher values suggested that supportive care alone would be preferable to palliative chemotherapy.

Table 1: Characteristics of the parents and children involved in the study

\begin{tabular}{cc}
\hline Characteristic & No. $(\%) *$ \\
$n=77$
\end{tabular}

\section{Parents}

Male sex

$17 \quad(22.1)$

Age, median, yr (IQR)

$40.0(35.7-45.3)$

Married

$65 \quad(84.4)$

Level of education

\begin{tabular}{lcc} 
High school & 23 & $(29.9)$ \\
\hline College or university & 42 & $(54.6)$ \\
\hline Professional or graduate degree & 12 & $(15.6)$ \\
\hline uality-of-life visual analogue scale, score (IQR) & 4.8 & $(2.1-7.0)$
\end{tabular}

\section{Children}

Male sex

$48 \quad(62.3)$

Age, median, yr (IQR)

$8.6 \quad(6.2-13.3)$

Time since diagnosis, median, yr (IQR)

$1.6 \quad(0.8-2.6)$

Form of cancer

\begin{tabular}{lrr} 
Leukemia & 18 & $(23.4)$ \\
\hline Lymphoma & 3 & $(3.9)$ \\
\hline Solid tumour & 32 & $(41.6)$ \\
\hline Brain tumour & 24 & $(31.2)$ \\
\hline Relapse & 56 & $(72.7)$ \\
\hline Treatment in the 4 wks before the study & & \\
$\quad$ Intravenous chemotherapy & 34 & $(44.2)$ \\
\hline Oral chemotherapy & 19 & $(24.7)$ \\
\hline Inpatient chemotherapy & 16 & $(20.8)$ \\
\hline Radiation & 13 & $(16.9)$ \\
\hline None & 21 & $(27.3)$ \\
Quality-of-life visual analogue scale, score (IQR) & 6.0 & $(3.0-8.0)$ \\
\hline
\end{tabular}

Note: $\mathrm{IQR}=$ interquartile range.

*Unless otherwise specified.

tChildren may have received more than one type of treatment.
Wilcoxon rank-sum analysis was used to test for across-groups differences in the distributions of desirability scores for supportive care using the attributes of quality of life and survival time. Linear regression models were used to examine the relations between potential predictors and desirability scores. Repeated-measures analysis of variance was used to determine whether desirability scores were affected by statements regarding the opinions of the physicians/parents and the child. For the repeated-measures analysis, we specified standard variance components in our covariance structure, because sensitivity analyses we conducted with extreme covariance structures showed almost identical results.

All tests of significance were two-sided, and statistical significance was defined as $p<0.05$.

\section{Results}

\section{Participants}

Between June 1, 2005, and Oct. 22, 2009, 115 eligible parents were identified. Fourteen children died before a parent could be approached. Two children were considered too medically unstable, eight families were considered too emotionally overwhelmed, and one child was transferred to another hospital before his parents could be approached. Twelve families refused to participate. At the start of one interview, the child became unwell and the parent was unable to continue. A total of 77 parents participated in the study. Distributions of age, sex or diagnosis of leukemia did not differ between participants and nonparticipants (data not shown). Table 1 describes the characteristics of the parents, children and their households. Among the parents, 31 $(40.3 \%)$ had children admitted to hospital at the time of interview. Of the 77 interviews, 31 were done in the inpatient setting, 43 in the outpatient setting and 3 in the families' homes.

Of the 129 health care professionals we approached, 128 agreed to participate in the study. Of these, $19(14.8 \%)$ were men and the median age was 34.2 years (interquartile range [IQR] 28.9-41.4). The health care professionals had been working with children with cancer for a median of 7.0 years (IQR 3.0-14.0). Among the respondents in this group were 13 staff physicians $(10.2 \%), 12$ senior fellows $(9.4 \%), 97$ nurses $(75.8 \%)$ and 6 social workers (4.7\%).

\section{Initially favoured options and influencing factors}

Significantly more parents $(42 / 77,54.5 \%)$ than health care professionals $(20 / 128,15.6 \%)$ favoured chemotherapy (Wilcoxon rank-sum test, $p<0.0001$ ). 
Table 2 lists the rank-ordering of the importance of factors influencing the choice between supportive care and chemotherapy for both parents and health care professionals. For parents, hope and the quality of life of their child were tied for the highest ranking, followed by increased survival time. For health care professionals, the child's quality of life was ranked as the most important factor, followed by increased survival time. The most common factors added to our original list by respondents were "child opinion" (health care professionals, $n=16$; parents, $n=9$ ) and "religion/faith/spirituality" (health care professionals, $n=5$; parents, $n=10$ ). ${ }^{11}$ Other factors added to the list included "previous experience of illness," "duration of illness" and "experimental treatments." Recall that these rankorders were elicited before the respondents engaged in the threshold tasks.

\section{Desirability scores}

Table 3 presents the median desirability scores for supportive care from both parents and health care professionals, as seen under the different measurement conditions. Under the quality-oflife condition, health care professionals gave a median score of 7.0 for supportive care, compared with the parents' median score of $3.0(p<$ 0.0001). Because the baseline quality of life was five units, health care professionals would require a median increment of two units in quality of life to be associated with chemotherapy before considering it worthwhile, whereas parents would accept chemotherapy even if it reduced quality of life by a median of two units.

Under the survival-time condition, health care professionals gave a median score of 8.0 for supportive care, compared with the parents' median score of $5.0(p<0.0001)$. Because the baseline survival time was six months, health care professionals would need a median increment of two months of survival time associated with chemotherapy before considering it worthwhile, whereas parents would accept chemotherapy even if it reduced survival time by a median of one month.

Health care professionals would need a median probability of cure of $5 \%$ before considering chemotherapy worthwhile.

\section{Predictors of desirability scores for supportive care}

Table 4 summarizes the results of linear regression models examining the relations between the potential predictors and the desirability scores parents gave to supportive care under the two measurement conditions. Married parents gave higher scores than single or unmarried parents, suggesting stronger preference for supportive care, under both measurement conditions; parents of older children also gave higher scores to supportive care under the survival-time condition. Parents gave low scores to supportive care, suggesting stronger preferences for palliative chemotherapy, when their children had recently received intravenous chemotherapy (under both measurement conditions), and when the children's current quality of life was low (under the survival-time condition).

Table 4 summarizes the results of the repeated-measures analysis of variance that was used to see whether parents' desirability scores were affected by the opinions of their physician or child. Under both measurement conditions, parents' scores matched those of the doctors and children. In all situations, the opinion of the child seemed to affect the scores given by parents more strongly than the opinion of the physician.

Table 5 summarizes the results of the linear regression models examining the relations between the potential predictors and the desirability scores given by health care professionals under each of the three measurement conditions. In all situations, the opinion of the child affected the reported desirability scores more strongly than the opinion of the parent. The responses provided by physicians and nonphysicians, in terms of the factors affecting their initially favoured choice and their desirability scores, were similar (data not shown).

\section{Interpretation}

We found that parents and health care professionals make similar considerations during endof-life decision-making. However, parents also

Table 2: Importance of factors influencing the choice between supportive care and palliative chemotherapy as ranked by parents and health care professionals

\begin{tabular}{|lccc|}
\hline & $\begin{array}{c}\text { Parents' ranking, } \\
\text { median (IQR) } \\
n=77\end{array}$ & $\begin{array}{c}\text { Health care } \\
\text { professionals' } \\
\text { ranking, } \\
\text { median (IQR) } \\
n=128\end{array}$ \\
\hline Factor & 2 & $(1-3)$ & $1(1-2)$ \\
\hline Child's quality of life & 2 & $(1-3)$ & $4(3-5)$ \\
\hline Hope & 3 & $(2-4)$ & $2(2-3.5)$ \\
\hline Increased survival time & 5 & $(4-6)$ & $4(3-5)$ \\
\hline Family's quality of life & 5 & $(3.5-6)$ & $7(6-8)$ \\
\hline $\begin{array}{l}\text { Opinion of healthcare } \\
\text { professionals* }\end{array}$ & 6.5 & $(6-8)$ & $5(4-6)$ \\
\hline $\begin{array}{l}\text { Financial considerations } \\
\text { Opinion of the parentst }\end{array}$ & 7 & $(6-7)$ & \\
\hline $\begin{array}{l}\text { Note: IQR = interquartile range. } \\
\text { *For the health care professional group, this factor refers to the opinions of other health } \\
\text { care professionals. } \\
\text { FFor the parent group, this factor refers to the opinions of other parents. }\end{array}$ \\
\hline
\end{tabular}


Table 3: Desirability of supportive care relative to chemotherapy as scored by parents and health care professionals by attribute used in threshold tasks

\begin{tabular}{|lccccc|}
\hline & & & \multicolumn{2}{c}{ Score, median (IQR) } & \\
\cline { 1 - 4 } Attribute & $\begin{array}{c}\text { Baseline } \\
\text { level }\end{array}$ & $\begin{array}{c}\text { Theoretical } \\
\text { minimum, } \\
\text { maximum scores }\end{array}$ & Parents & $\begin{array}{c}\text { Health care } \\
\text { professionals }\end{array}$ & $p$ value \\
\hline Quality of life, units & 5 & 0,10 & $3.0(1.0-7.0)$ & $7.0(6.0-7.5)$ & $<0.0001$ \\
\hline Survival time, mo & 6 & 0,12 & $5.0(3.0-8.0)$ & $8.0(7.0-10.0)$ & $<0.0001$ \\
\hline Probability of cure, \% & 1 & 0,10 & NA & $5.0(2.0-10.0)$ & NA \\
\hline Note: IQR = interquartile range, NA = not applicable. & & & \\
\hline
\end{tabular}

Table 4: Predictors of desirability scores 77 parents gave to supportive care (relative to chemotherapy), by attribute used during threshold tasks

\begin{tabular}{|c|c|c|c|c|}
\hline Predictor & $\begin{array}{l}\text { Quality of } \\
\text { life*, } \\
\text { units (SE) }\end{array}$ & $p$ value & $\begin{array}{l}\text { Survival time*, } \\
\text { mo (SE) }\end{array}$ & $p$ value \\
\hline \multicolumn{5}{|l|}{ Characteristics of respondent } \\
\hline Male sex & $-0.30(0.91)$ & 0.74 & $-0.44(1.05)$ & 0.68 \\
\hline Age, yr & $0.08(0.06)$ & 0.21 & $0.12(0.07)$ & 0.06 \\
\hline Married & $2.11(1.01)$ & 0.04 & $2.71(1.16)$ & 0.02 \\
\hline Current quality of life & $0.17(0.14)$ & 0.21 & $0.01(0.16)$ & 0.94 \\
\hline \multicolumn{5}{|l|}{ Characteristics of child } \\
\hline Male sex & $0.63(0.77)$ & 0.42 & $0.18(0.90)$ & 0.84 \\
\hline Age, yr & $0.12(0.08)$ & 0.14 & $0.19(0.09)$ & 0.03 \\
\hline Time since diagnosis, yr & $0.18(0.18)$ & 0.32 & $0.39(0.20)$ & 0.06 \\
\hline \multicolumn{5}{|l|}{ Diagnosis } \\
\hline Leukemia & $-1.77(0.96)$ & 0.07 & $-1.36(1.13)$ & 0.23 \\
\hline Lymphoma & $1.28(1.96)$ & 0.52 & $-0.14(2.32)$ & 0.95 \\
\hline Solid tumour (reference) & 1.00 & & 1.00 & \\
\hline Brain tumour & $-0.76(0.88)$ & 0.39 & $-0.89(1.04)$ & 0.40 \\
\hline Relapse & $-0.56(0.84)$ & 0.51 & $0.35(0.98)$ & 0.73 \\
\hline \multicolumn{5}{|l|}{ Treatment during previous 4 wks } \\
\hline Intravenous chemotherapy & $-1.68(0.73)$ & 0.02 & $-1.72(0.86)$ & 0.05 \\
\hline Oral chemotherapy & $0.12(0.87)$ & 0.89 & $0.80(1.01)$ & 0.43 \\
\hline Inpatient chemotherapy & $-1.33(0.92)$ & 0.15 & $-0.94(1.07)$ & 0.38 \\
\hline Radiation & $1.25(1.00)$ & 0.21 & $1.27(1.16)$ & 0.28 \\
\hline None & $1.48(0.83)$ & 0.08 & $1.42(0.97)$ & 0.14 \\
\hline Current quality of life & $-0.12(0.13)$ & 0.35 & $-0.34(0.14)$ & 0.02 \\
\hline \multicolumn{5}{|l|}{ Opinions of others } \\
\hline Doctor prefers intravenous chemotherapy & $-1.17(0.26)$ & 0.02 & $-1.44(0.33)$ & 0.01 \\
\hline Doctor prefers supportive care alone & $1.55(0.29)$ & 0.002 & $1.25(0.31)$ & 0.02 \\
\hline Child prefers intravenous chemotherapy & $-2.62(0.31)$ & $<0.0001$ & $-3.19(0.40)$ & $<0.0001$ \\
\hline Child prefers supportive care alone & $2.61(0.32)$ & $<0.0001$ & $2.22(0.35)$ & $<0.0001$ \\
\hline \multicolumn{5}{|c|}{$\begin{array}{l}\text { Note: } \mathrm{SE}=\text { standard error. } \\
{ }^{*} \text { Change needed to be associated with chemotherapy for the respondent to find chemotherapy worthwhile. For example, in } \\
\text { the quality-of-life analysis, } 2.11 \text { for "Married" means that married respondents would require an increase of } 2.11 \text { units of } \\
\text { quality-of-life to be associated with chemotherapy before they would find chemotherapy worthwhile, reflecting a stronger } \\
\text { preference for supportive care. }\end{array}$} \\
\hline
\end{tabular}


focus on the importance of hope; this factor may loom larger for parents than for health care professionals. Given their relatively scant experience with the outcomes of similar children, parents may focus more on hope for their child compared with health care professionals, who are more aware of eventual outcomes given their experiences with many similar children.

Health care professionals, as a group, tended to regard supportive care alone more positively than did parents, implying that parents and health care professionals generally have different underlying attitudes toward end-of-life treatments. These underlying differences may, in part, contribute to the apparent conflict between professionals and parents when tensions emerge during the palliative phase of care.

Despite the high importance ranking they assigned to their child's quality of life, parents reported that they would accept chemotherapy even if it reduced both quality of life and survival time. This finding shows the complexity of decisionmaking. It is possible that hope for a cure is such an important factor that it may override considerations of the child's quality of life and survival time.

Another unexpected result was the strong effect of parental marital status on desirability scores. Single parents may be more resistant to giving up aggressive treatment if they lack a supportive family structure. Further investigation of this association is warranted.
When we elicited parental desirability scores, we focused on two attributes: child quality of life and survival time. However, these attributes are typically unknown in most clinical situations. Thus, the measurement of a child's quality of life and its association with palliative chemotherapy should be a research priority.

Hope has been identified as an important factor for parents to consider in their decision-making in several previous studies. ${ }^{6,11-15}$

For both parents and health care professionals, desirability scores were highly influenced by the opinions of the physician/parent and child. These results are congruent with a report that described the two highest-scoring factors that parents consider when caring for children with cancer as "recommendations received from health care professionals" and "things my child said about continuing or not continuing treatment." ${ }^{\text {Th }}$ These results imply that it is important to explicitly elicit the preferences of children, if their age and cognitive functioning so allow.

\section{Limitations}

Because only 77 of the 115 families we identified agreed to participate in the study, there is a potential for selection bias.

There is a spectrum of intensities for palliative chemotherapy and the mode of its administration. We chose to focus only on intravenous cytotoxic palliative chemotherapy. It is possible

Table 5: Predictors of desirability scores 128 health care professionals gave to supportive care (relative to chemotherapy), by attribute used during threshold tasks

\begin{tabular}{|c|c|c|c|c|c|c|}
\hline Predictor & $\begin{array}{l}\text { Quality of life*, } \\
\text { units (SE) }\end{array}$ & $p$ value & $\begin{array}{l}\text { Survival time*, } \\
\text { mo (SE) }\end{array}$ & $p$ value & $\begin{array}{c}\text { Probability of cure*, } \\
\% \text { (SE) }\end{array}$ & $p$ value \\
\hline \multicolumn{7}{|l|}{ Characteristic of respondent } \\
\hline Male sex & $-0.94(0.46)$ & 0.04 & $-1.09(0.59)$ & 0.07 & $-1.79(1.01)$ & 0.08 \\
\hline Age, yr & $0.01(0.02)$ & 0.59 & $0.01(0.02)$ & 0.59 & $0.05(0.04)$ & 0.25 \\
\hline $\begin{array}{l}\text { Experience with pediatric } \\
\text { cancer, yr }\end{array}$ & $0.01(0.02)$ & 0.64 & $0.01(0.03)$ & 0.76 & $0.07(0.04)$ & 0.11 \\
\hline $\begin{array}{l}\text { Physician v. other health care } \\
\text { professional }\end{array}$ & $0.32(0.58)$ & 0.59 & $0.52(0.69)$ & 0.45 & $-1.08(0.90)$ & 0.23 \\
\hline \multicolumn{7}{|l|}{ Opinion of others } \\
\hline $\begin{array}{l}\text { Parent prefers intravenous } \\
\text { chemotherapy }\end{array}$ & $-1.61(0.20)$ & $<0.0001$ & $-2.49(0.27)$ & $<0.0001$ & $-2.97(0.37)$ & $<0.0001$ \\
\hline $\begin{array}{l}\text { Parent prefers supportive } \\
\text { care alone }\end{array}$ & $1.54(0.16)$ & $<0.0001$ & $1.49(0.22)$ & $<0.0001$ & $1.77(0.28)$ & $<0.0001$ \\
\hline $\begin{array}{l}\text { Child prefers intravenous } \\
\text { chemotherapy }\end{array}$ & $-2.85(0.21)$ & $<0.0001$ & $-3.70(0.29)$ & $<0.0001$ & $-4.16(0.37)$ & $<0.0001$ \\
\hline $\begin{array}{l}\text { Child prefers supportive care } \\
\text { alone }\end{array}$ & $2.32(0.17)$ & $<0.0001$ & $2.54(0.20)$ & $<0.0001$ & $2.50(0.30)$ & $<0.0001$ \\
\hline \multicolumn{7}{|c|}{$\begin{array}{l}\text { Note: SE = standard error } \\
\text { "Change needed to be associated with chemotherapy for the respondent to find chemotherapy worthwhile. For example, in the quality-of-life analysis, } 1.54 \text { for } \\
\text { "Parent prefers supportive care alone" means that respondents would require an increase of } 1.54 \text { units of quality-of-life to be associated with chemotherapy } \\
\text { before they would find chemotherapy worthwhile. }\end{array}$} \\
\hline
\end{tabular}


that preferences would differ if chemotherapy were administered orally, even if the chemotherapy were cytotoxic.

Our ethically driven decision not to use probability of cure as an attribute during the parents' threshold task prevented us from learning how parents view this factor. In view of the high ranking that parents assigned to hope, if we had worked with probability of cure, we might have seen a strong effect on the desirability scores reported by parents. In addtion, the threshold task involving survival time considered only length of survival without explicit adjustment for quality of life.

We used a proxy measure of child quality of life rather than childrens' self reports, which may have introduced additional bias.

Most of the health care professionals who participated in our study were nurses. Nurses typically do not make decisions regarding chemotherapy versus supportive care, thus limiting the usefulness of our results. However, we did not find differences across types of professionals in terms of their reported desirability scores.

Finally, although the families participating in our study had a child whose cancer had no reasonable chance of cure, we asked them to make decisions in a hypothetical situation; their actual decisions could differ.

\section{Conclusion}

This study provides insight into the different perspectives on treatment that may be held by children's families and their health care professionals during end-of-life care. In particular, the study highlights the need to educate clinicians about the ways in which different groups may hold different attitudes toward aggressive chemotherapy. Future research should quantify quality of life and survival time with palliative chemotherapy and identify how best to convey this information to families when providing them with individualized support while they make decisions concerning end-of-life care.

\section{References}

1. Kamps WA, Akkerboom JC, Kingma A, et al. Experimental chemotherapy in children with cancer-a parent's view. Pediatr Hematol Oncol 1987;4:117-24.

2. Fields MF, Behrman RE, editors. When children die: improving palliative and end-of-life care for children and their families. Washington (DC): The National Academies Press; 2003.

3. American Cancer Society. Cancer facts \& figures 2010. Atlanta (GA): The Society; 2010. Available: www.cancer.org/Research /CancerFactsFigures/CancerFactsFigures/cancer-facts-and-figures -2010 (accessed 2010 Oct. 2).

4. Health Canada. Leading causes of death and hospitalization in Canada [Table 1]. Ottawa (ON): Public Health Agency of Canada; 2010. Available: www.phac-aspc.gc.ca/publicat/lcd-pcd 97/table1-eng.php (accessed 2010 Oct. 2).
5. Hinds PS, Oakes L, Furman W, et al. Decision making by parents and health care professionals when considering continued care for pediatric patients with cancer. Oncol Nurs Forum 1997; 24:1523-8.

6. Barrera M, D'Agostino N, Gammon J, et al. Health-related quality of life and enrollment in phase 1 trials in children with incurable cancer. Palliat Support Care 2005;3:191-6.

7. Hinds PS, Oakes L, Quargnenti A, et al. An international feasibility study of parental decision making in pediatric oncology. Oncol Nurs Forum 2000;27:1233-43.

8. Tomlinson D, Capra M, Gammon J, et al. Parental decision making in pediatric cancer end-of-life care: using focus group methodology as a prephase to seek participant design input. Eur J Oncol Nurs 2006;10:198-206.

9. Llewellyn-Thomas HA. Patients' health-care decision making: a framework for descriptive and experimental investigations. Med Decis Making 1995;15:101-6.

10. Llewellyn-Thomas HA. Threshold technique. In: Kattan MW, editor. Encyclopedia of medical decision making. Thousand Oaks (CA): Sage Publications; 2009. p. 1134-7.

11. Tomlinson D, Bartels U, Hendershot E, et al. Factors affecting treatment choices in pediatric palliative care: comparing parents and health care professionals. Eur J Cancer 2011; Jun 11. [Epub ahead of print].

12. Maurer SH, Hinds PS, Spunt SL, et al. Decision making by parents of children with incurable cancer who opt for enrollment on a phase I trial compared with choosing a do not resuscitate/terminal care option. J Clin Oncol 2010;28:3292-8.

13. Fletcher PC, Schneider MA, Harry RJ. How do I cope? Factors affecting mothers' abilities to cope with pediatric cancer. J Pediatr Oncol Nurs 2010;27:285-98.

14. Liu YM, Yeh CH. Pediatric oncology: the use of cluster analysis to examine maternal concerns. Oncol Nurs Forum 2010;37: E304-11.

15. Mack JW, Wolfe J, Cook EF, et al. Hope and prognostic disclosure. J Clin Oncol 2007;25:5636-42.

Affiliations: From the Child Health Evaluative Sciences (Tomlinson, Greenberg, Sung), the Division of Haematology/Oncology (Bartels, Gammon, Volpe, Bouffet, Baruchel, Greenberg, Barrera, Sung) and the Department of Psychology (Barrera), The Hospital for Sick Children, Toronto, Ont.; the Department of Nursing Research and Quality Outcomes (Hinds), Children's National Medical Center, and Department of Pediatrics (Hinds), The George Washington University, Washington, DC; Fred Hutchinson Cancer Research Center (Regier), University of Washington, Seattle, Wash.; and the Department of Community and Family Medicine (Llewellyn-Thomas), Dartmouth Medical School, Dartmouth College, Hanover, NH.

Contributors: Deborah Tomlinson contributed substantially to the conception and design of the study and the acquisition and interpretation of the data, drafted the article and revised it critically for important intellectual content, and gave final approval of the version to be published. Ute Bartels, Janet Gammon, Pamela S. Hinds, Jocelyne Volpe, Eric Bouffet, Dean A. Regier, Sylvain Baruchel, Mark Greenberg, Maru Barrera and Hilary Llewellyn-Thomas contributed substantially to the conception and design of the study, revised the article critically for important intellectual content, and gave final approval of the version to be published. Lillian Sung contributed substantially to the conception and design of the study and the analysis and interpretation of the data, drafted the article and revised it critically for important intellectual content, and gave final approval of the version to be published.

Funding: This work was supported by the Canadian Cancer Society (grant no. 016388). Lillian Sung is supported by the Canadian Institutes of Health Research through a New Investigator Award (grant no. 87719).

Acknowledgement: The authors thank Dan Fulsang for his artistic expertise in producing the illustrations representing "Chance of Cure" that were used in the health care providers' threshold tasks. 